XX Міжнародний симпозіум «Методи дискретних особливостей в задачах математичної фізики/Discrete Singularities Methods in Mathematical Physics»,

УДК 532.5.031:004.942

MSC 76D17

\title{
Numerical scheme for calculating the boundary layer when modeling by the method of discrete vortices
}

\author{
S.O. Dovgiy \\ Institute of Telecommunications and Global Information Space, Kyiv, Ukraine \\ E-mail: itelua@kv.ukrtel.net \\ G.G. Bulanchuk \\ Pryazovskyi State Technical University, Mariupol, Ukraine \\ E-mail: ggbulan7@gmail.com \\ O.M. Bulanchuk \\ Donetsk State University of Management, Mariupol, Ukraine \\ E-mail: obulan65@gmail.com

\begin{abstract}
In this paper, a six-point finite-difference numerical scheme for calculating the Prandtl equation of a laminar boundary layer is proposed to determine the point of separation of flows with large Reynolds numbers when flowing around smooth bodies. The input data for this scheme are the results of modeling by the method of discrete vortices within the model of an ideal fluid. The velocity profile around the critical point is determined from the analytical solution. The resulting system of linear algebraic equations is solved by the run method. Because the coefficients of the system are nonlinear, the iteration method is used to find the solution. The thickness of the boundary layer is determined during the solution process. The point of separation and circulation of descending vortices is determined from the calculation of the boundary layer. Then at the point of separation the rise of several free vortices is modeled, the dynamics of which is modeled within the method of discrete vortices. The scheme was tested on the problem of the flow around the cylinder and showed good results in comparison with the experimental data and calculations of other authors.
\end{abstract}

Key words: discrete vortex method, Prandtl equation, boundary layer equation, separation point, vortex descent.

\section{Чисельна схема розрахунку пограничного шару при моделюванні методом дискретних вихорів С.О. Довгий}

Інститут телекомунікацій та глобального інформаційного простору, Київ, Україна E-mail: itelua@kv.ukrtel.net

Г.Г. Буланчук

ДВНЗ “Приазовський державний технічний університет”, Маріуполь, Україна E-mail: ggbulan7@gmail.com

О.М. Буланчук

Донецький державний університет управління, Маріуполь, Україна E-mail: obulan65@gmail.com

У даній роботі для визначення точки відриву течій із великими числами Рейнольдса при обтіканні гладких тіл пропонується шеститочкова кінцево-різницева чисельна схема розрахунку рівняння Прандтля ламінарного пограничного шару. Вхідними даними для даної схеми $\epsilon$ результати моделювання методом дискретних ви-

(с) Довгий С.О., Буланчук Г.Г., Буланчук О.М., 2021 


\begin{abstract}
хорів у рамках моделі ідеальної рідини. Профіль швидкості в околі критичної точки визначається із аналітичного розв'язку. Отримана система лінійних алгебраїчних рівнянь розв'язується методом прогонки. Оскільки коефіцієнти системи є нелінійними, то для знаходження розв'язку використовується метод ітерацій. Товщина пограничного шару визначається в процесі розв'язку. Точка відриву та циркуляції вихорів, що сходять, отримуються із розрахунку пограничного шару. Потім в точці відриву моделюється схід вільних вихорів, динаміка яких визначається в рамках методу дискретних вихорів. Схема була апробована на задачі обтікання циліндра i показала добрі результати в порівнянні з експериментальними даними та розрахунками інших авторів.
\end{abstract}

Ключові слова: метод дискретних вихорів, рівняння Прандтля, рівняння пограничного шару, точка відриву, схід вихорів.

\title{
1. Вступ
}

На сьогодні теорія ламінарних і турбулентних пограничних шарів продовжує розвиватись і $є$ самостійною областю механіки рідини і газу. Під пограничним шаром розуміють тонку область вихрової течії, де різко змінюється швидкість потоку. Якщо характер течії у пограничному шарі ламінарний, то розглядають ламінарний пограничний шар. Основна умова його утворення - значне число Рейнольдса. Рівняння ламінарного пограничного шару було отримане Прандтлем у 1904 році [1] і має вигляд:

$$
\begin{aligned}
& \frac{\partial u}{\partial t}+u \frac{\partial u}{\partial x}+v \frac{\partial u}{\partial y}=-\frac{1}{\rho} \frac{\partial p}{\partial x}+v \frac{\partial^{2} u}{\partial y^{2}} \\
& \frac{\partial u}{\partial x}+\frac{\partial v}{\partial y}=0 .
\end{aligned}
$$

Вихори, що утворились біля поверхні тіла, зносяться зовнішнім потоком (конвекція) і дифундують за рахунок в'язкості. Якщо явище конвекції переважає, то пограничний шар залишається досить тонким, його відносна товщина має порядок

$$
O\left(\frac{1}{\sqrt{R_{e}}}\right) .
$$

У методі дискретних вихорів [2, 3] використовується модель ідеальної рідини, тому зазвичай розглядають інерційний відрив потоку з гострих крайок. Інтерес до пограничного шару в даному методі викликаний бажанням врахувати в'язкий відрив від поверхні тіла гладкої форми. Це, зокрема, можна зробити при спільному використанні моделі ідеальної рідини для зовнішнього потоку і моделі пограничного шару біля тіла.

У роботі [4] була запропонована чисельна схема розрахунку нестаціонарного ламінарного пограничного шару і наведені ряд результатів. Однак, основні роботи, на які посилаються в цій книзі, недоступні і даний напрямок не отримав подальшого розвитку, хоча, ми вважаємо, є досить перспективним.

Тому в даній роботі розглянута дещо інша схема інтегрування пограничного шару, яка може бути використана для знаходження точки в'язкого відриву з подальшим використанням у методі дискретних вихорів для сходу вільних вихорів. 
XX Міжнародний симпозіум «Методи дискретних особливостей в задачах математичної фізики/Discrete Singularities Methods in Mathematical Physics»,

\section{МДОЗМФ/DSMМPh-2021}

\section{2. Чисельна схема пограничного шару}

Задача розв'язувалась у безрозмірному вигляді. За характерні розміри вибрано модуль швидкості на нескінченності $v_{\infty}$ та величину $D$, наприклад, діаметр циліндра, якщо ми розглядаємо обтікання циліндра. Безрозмірні величини будуть мати вигляд:

$$
\tilde{u}=\frac{u}{v_{\infty}}, \tilde{v}=\frac{v}{v_{\infty}}, \tilde{p}=\frac{p}{\rho v_{\infty}^{2} / 2}, \tilde{x}=\frac{x}{D}, \tilde{y}=\frac{y}{D}, \tau=\frac{t}{D / v_{\infty}} .
$$

Тоді рівняння (1) у безрозмірних координатах буде мати вигляд:

$$
\begin{aligned}
& \frac{\partial \tilde{u}}{\partial \tau}+\tilde{u} \frac{\partial \tilde{u}}{\partial \tilde{x}}+\tilde{v} \frac{\partial \tilde{u}}{\partial \tilde{y}}=-\frac{1}{2} \frac{\partial \tilde{p}}{\partial \tilde{x}}+\frac{1}{R_{e}} \frac{\partial^{2} \tilde{u}}{\partial \tilde{y}^{2}}, \\
& \frac{\partial \tilde{u}}{\partial \tilde{x}}+\frac{\partial \tilde{v}}{\partial \tilde{y}}=0,
\end{aligned}
$$

де $R_{e}=\frac{v_{\infty} D}{v}-$ число Рейнольдса.

Хоча ми розглядаємо нестаціонарний процес, але на кожному кроці по часу ми вважаємо, що пограничний шар стаціонарний, тому розв'язуємо рівняння (2) в припущенні, що $\frac{\partial \tilde{u}}{\partial \tau}=0$.

Для розв'язку рівняння (2) використовувалась шеститочкова чисельна схема (рис.1). При переході від одного шару до іншого кривизною поверхні нехтували, вважаючи що на одному кроці радіус кривизни поверхні значно більший ніж відстань між вузлами. Шар з індексом ј знаходиться в контрольній точці. Розрахунки проводились послідовно, рухаючись від критичної точки (на малюнку показано рух зліва направо) по перерізам пограничного шару. В якості початкового профілю швидкості використовувався точний розв'язок рівняння Нав'є-Стокса в околі кри-

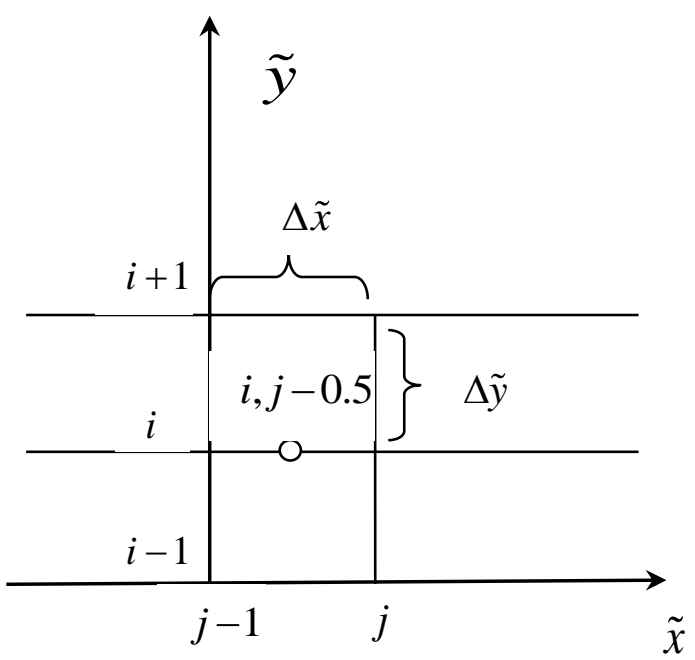

Рисунок 1. Шеститочкова чисельна схема пограничного шару 
тичної точки [5]. Переріз пограничного шару будемо позначати індексом $j$. Всі величини у формулі (2) обчислювались у середній точці $\left(\tilde{x}_{i, j-0.5}\right)$ (рис.1).

Значення величин в цій точці знаходились як середні значення у вузлових точках $j-1$ і $j$. Похідні по $\tilde{x}$ визначались, відповідно, по значенням $u_{j}$ i $u_{j-1}$, a похідні по $\tilde{y}-$ по середнім значенням між $j-1 \mathrm{i} j$ в точці $i+1$ і в точці $i-1$. Отримаємо наближені формули:

$$
\begin{aligned}
& \tilde{u}_{i, j-0.5}=0.5\left(\tilde{u}_{i, j-1}+\tilde{u}_{i, j}\right), \\
& \tilde{u} \frac{\partial \tilde{u}}{\partial \tilde{x}} \approx \tilde{u}_{i, j-0.5} \frac{\tilde{u}_{i, j}-\tilde{u}_{i, j-1}}{\Delta \tilde{x}}, \\
& \tilde{v}_{i, j-0.5}=0.5\left(\tilde{v}_{i, j-1}+\tilde{v}_{i, j}\right), \\
& \tilde{v} \frac{\partial \tilde{u}}{\partial \tilde{y}} \approx \tilde{v}_{i, j-0.5} \cdot\left(\frac{0.5\left(\tilde{u}_{i+1, j-1}+\tilde{u}_{i+1, j}\right)-0.5\left(\tilde{u}_{i-1, j-1}+\tilde{u}_{i-1, j}\right)}{2 \Delta \tilde{y}}\right)= \\
& =\frac{\tilde{v}_{i, j-0.5}}{4 \Delta \tilde{y}}\left[\tilde{u}_{i+1, j-1}-\tilde{u}_{i-1, j-1}+\tilde{u}_{i+1, j}-\tilde{u}_{i-1, j}\right] .
\end{aligned}
$$

Традиційно вважаємо, що тиск у поперечному перерізі пограничного шару не змінюється і дорівнює тиску ідеальної рідини зовнішньої течії. Із формули Бернулі для зовнішнього обтікання ( $v_{3}-$ швидкість ідеальної рідини зовнішньої течії) маємо:

$$
p+\frac{\rho v_{3}^{2}}{2}+\rho g y=\text { const } .
$$

Продиференціюємо цей вираз по $x$. Будемо мати:

$$
\frac{\partial p}{\partial x}=-\rho v_{3} \frac{\partial v_{3}}{\partial x}
$$

Із врахуванням безрозмірних координат отримаємо

$$
\frac{\partial \tilde{p}}{\partial \tilde{x}}=-2 \tilde{v}_{3} \frac{\partial \tilde{v}_{3}}{\partial \tilde{x}}
$$

де $\tilde{v}_{3}=v_{3} / v_{\infty}$

Наближена формула для обчислення $\frac{\partial \tilde{p}}{\partial \tilde{x}}$ буде мати вигляд:

$$
\frac{\partial \tilde{p}}{\partial \tilde{x}} \approx-2 \tilde{v}_{3 i, j-0.5} \frac{\tilde{v}_{3 i, j}-\tilde{v}_{3 i, j-1}}{\Delta \tilde{x}} .
$$

Для обчислення доданку $\frac{1}{R_{e}} \frac{\partial^{2} \tilde{u}}{\partial \tilde{y}^{2}}$ у рівнянні (2) знаходилась похідна від першої похідної за аналогічною схемою наближення. Використовувалась формула 
XX Міжнародний симпозіум «Методи дискретних особливостей в задачах математичної фізики/Discrete Singularities Methods in Mathematical Physics»,

$\frac{1}{R_{e}} \frac{\partial^{2} \tilde{u}}{\partial \tilde{y}^{2}} \approx$

$\approx \frac{1}{R_{e}}\left[\frac{0.5\left(\tilde{u}_{i+1, j-1}+\tilde{u}_{i+1, j}\right)-0.5\left(\tilde{u}_{i, j-1}+\tilde{u}_{i, j}\right)}{\Delta \tilde{y}}-\frac{0.5\left(u_{i, j-1}+u_{i, j}\right)-0.5\left(u_{i-1, j-1}+u_{i, j}\right)}{\Delta \tilde{y}}\right] / \Delta \tilde{y}$.

Якщо всі ці доданки підставити у перше рівняння (2) і згрупувати, то отримаємо рівняння в перерізі $j$ відносно невідомих $u_{i-1, j}, u_{i, j}$ i $u_{i+1, j}$, яке буде мати вигляд:

$$
\begin{aligned}
& \tilde{u}_{i-1, j}\left(-\frac{\tilde{v}_{i, j-0.5}}{4 \Delta \tilde{y}}-\frac{1}{2 R_{e} \Delta \tilde{y}^{2}}\right)+\tilde{u}_{i, j}\left(-\frac{\tilde{u}_{i, j-0.5}}{4 \Delta \tilde{x}}+\frac{1}{R_{e} \Delta \tilde{y}^{2}}\right)+ \\
& +\tilde{u}_{i+1, j}\left(\frac{\tilde{v}_{i, j-0.5}}{4 \Delta \tilde{y}}-\frac{1}{2 R_{e} \Delta \tilde{y}^{2}}\right)=b_{i j} .
\end{aligned}
$$

Права частина $b_{i j}$ виражена через величини перерізу $j-1$ і обчислюється за формулою:

$b_{i j}=\tilde{u}_{i-1, j} \cdot \frac{\tilde{u}_{i, j-1}}{\Delta \tilde{x}}-\frac{\tilde{v}_{i, j-0.5}}{4 \Delta \tilde{y}}\left(\tilde{u}_{i+1, j-1}-\tilde{u}_{i-1, j-1}\right)+\tilde{v}_{3} \frac{\partial \tilde{v}_{3}}{\partial \tilde{x}}+\frac{1}{2 R_{e} \Delta \tilde{y}^{2}}\left(\tilde{u}_{i+1, j-1}-2 \tilde{u}_{i, j-1}+\tilde{u}_{i-1, j-1}\right)$.

Величину $\tilde{v}_{i, j-0.5}$, що входить в ці формули, обчислимо, використавши рівняння нерозривності в точці $(i-0.5, j-0.5)$ (рис.2).

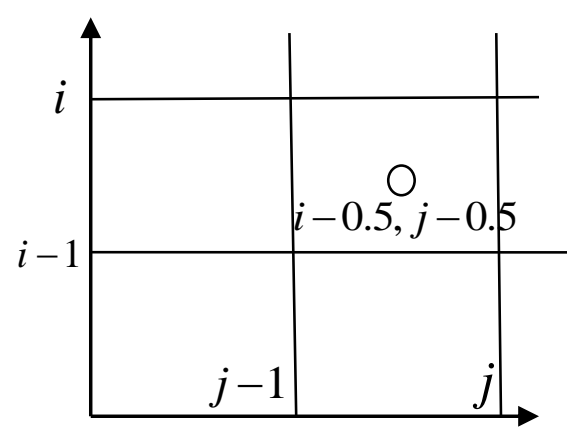

Рисунок 2. Розрахункова сітка

У рівнянні нерозривності системи (2) доданки апроксимуються за формулами:

$$
\begin{aligned}
& \frac{\partial \tilde{u}}{\partial \tilde{x}} \approx \frac{0.5\left(u_{i, j}+u_{i-1, j}\right)-0.5\left(u_{i, j-1}+u_{i-1, j-1}\right)}{\Delta \tilde{x}}, \\
& \frac{\partial \tilde{v}}{\partial \tilde{y}} \approx \frac{v_{i, j-0.5}-v_{i-1, j-0.5}}{\Delta \tilde{y}},
\end{aligned}
$$


Підставимо ці доданки у рівняння нерозривності системи (2) і виразимо $v_{i, j-0.5}$. Тоді для знаходження $v_{i, j-0.5}$ будемо мати:

$$
v_{i, j-0.5}=v_{i-1, j-0.5}-\frac{\Delta \tilde{y}}{\Delta \tilde{x}} \cdot\left(0.5\left(u_{i, j}+u_{i-1, j}\right)-0.5\left(u_{i, j-1}+u_{i-1, j-1}\right)\right) .
$$

Таким чином, у результаті ми отримаємо систему (3) 3 тридіагональною матрицею відносно невідомих коефіцієнтів біля $\tilde{u}_{i-1, j}, \tilde{u}_{i, j}, \tilde{u}_{i+1, j}$. Слід зазначити, що коефіцієнти матриці і права частина самі залежать від швидкостей $\tilde{u}_{i-1, j}, \tilde{u}_{i, j}, \tilde{u}_{i+1, j}$, тому система насправді є нелінійною і розв'язується методом ітерацій. Для кожної ітерації використовується метод прогонки. Таким чином, маємо два цикли: зовнішній ітераційний та внутрішній - метод прогонки. Ітерації продовжуються, поки відносна зміна швидкостей на двох послідовних ітераціях не стане меншою за певне значення. Після цього визначається товщина пограншару із умови, щоб значення у зовнішній точці пограншару не відрізнялося більше ніж на один відсоток від значення, що дає модель ідеальної рідини. При цьому товщина пограншару є невідомою величиною, за початкове значення було вибрано значення $\delta / D=1 / \sqrt{\operatorname{Re}}$. Біля критичної точки реальна товщина пограншару була меншою ніж оціночна. Тому при розрахунку першого шару визначалася його товщина, яка потім поступово збільшувалася, якщо умова для товщини не виконувалася. Якщо ця умова виконувалася раніше ніж задане наперед значення, то кількість точок у програншарі запам'ятовувалася і на наступному кроці бралася із попереднього. Якщо умова не виконувалася, то шар потовщувався і ітерації продовжувалися, а значення швидкостей бралися із попередніх ітерацій. Після знаходження точки відриву на кожному кроці по часу розв'язується задача обтікання тіла ідеальною рідиною методом дискретних вихорів: знаходиться сумарна циркуляція в точці відриву за методикою викладеною в [4], яка присвоюється вільному вихору, що сходить у потік. Розрахунки проводились до моменту появи вторинних відривів.

\section{3. Результати розрахунків для циліндра}

Схема була апробована на прикладі обтікання циліндра при числі Рейнольдса $\mathrm{Re}=10000$. У початковий момент часу обчислена точка відриву знаходилась у куті $104^{0}$ від передньої критичної точки, що досить близько до розрахунку по методу Кочіна-Лойцянського [6] $\left(103.12^{0}\right)$ Розрахунки проводилися 3 двома точками відриву. Перевірявся самий простий та швидкий варіант розрахунку. Для сходження вибирався один вихор в одній точці відриву. Час розрахунку для одного кроку по часу становив 0.08 с: час розрахунку для ідеальної рідини за методом дискретних вихорів для 180 точок на циліндрі на одному кроці по часу становив $0.05 \mathrm{c}$. , розрахунок пограншару для двох точок займав $0.03 \mathrm{c}$.

У даному дослідженні з'ясувалося, що результат істотно залежить від кроку по часу. Коли крок становив 0.07 , то за 7 кроків по часу встановлювалась точка відриву на куті $80^{\circ}$, що майже співпадає з експериментальними даними $\left(81^{0}\right)$.

3'ясувалося, що величина кроку по часу впливає на результат розрахунків, при виході кроку по часу за певний діапазон результати не співпадали з експериментом. Критерієм визначення точок відриву було перевищення числа ітерацій 500. В 
XX Міжнародний симпозіум «Методи дискретних особливостей в задачах математичної фізики/Discrete Singularities Methods in Mathematical Physics»,

\section{МДОЗМФ/DSMMPh-2021}

таблиці 1 представлено значення кута, на якому відбувається відрив в залежності від кроку по часу. Із результатів чисельного експерименту зокрема слідує, що найкращі результати отримуються, коли середня швидкість у перерізі, де відбувається відрив $v_{s}$ і товщина пограншару пов'язані співвідношенням $v_{s} \Delta t \approx 4 \delta \div 5 \delta$.

Таблиця 1

\begin{tabular}{|l|l|l|l|l|l|l|}
\hline$\Delta t$ & 0.05 & 0.06 & 0.07 & 0.08 & 0.09 & 0.1 \\
\hline$\varphi$ & $74^{0}$ & $76^{0}$ & $80^{0}$ & $80^{0}$ & $82^{0}$ & $84^{0}$ \\
\hline
\end{tabular}

На рис.3 показано результат положення вихорів у момент часу $\tau=0.49$, точка відриву знаходиться в куті $80^{\circ}$.

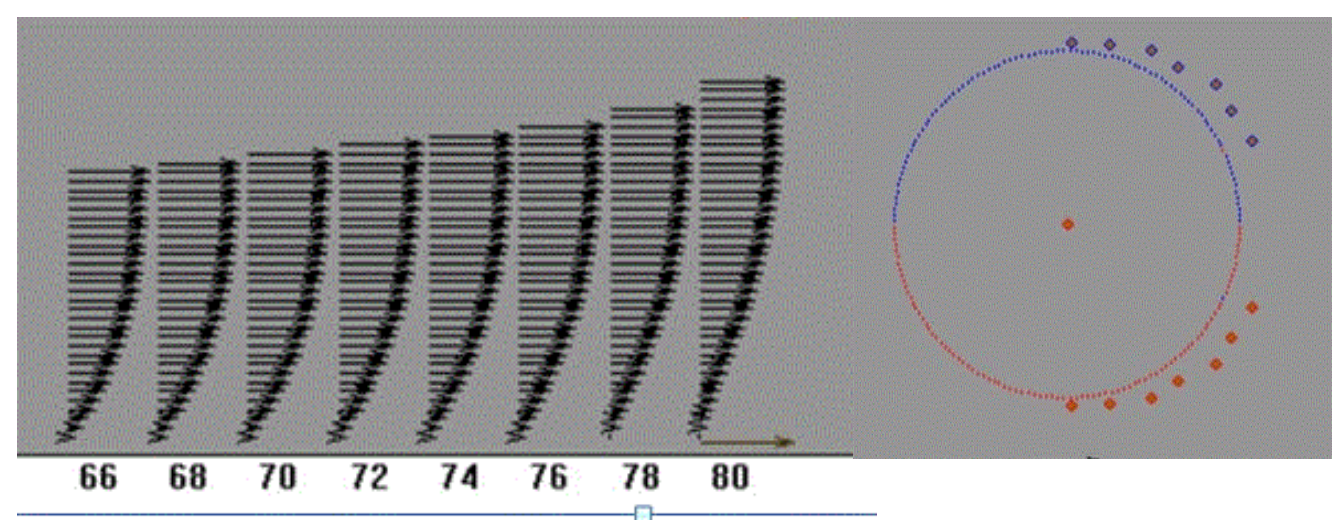

Рис. 3 Положення вільних вихорів за циліндром та профілі повздовжньої швидкості в момент часу $\tau=0.49, \varphi=80^{\circ}$

\section{ЛІТЕРАТУРА}

1. Лойцянский Л.Г. Механика жидкости и газа. М.: Наука, 2001.

2. Белоцерковский С.М. Ништ М.И. Отрывное и безотрывное обтекание тонких крыльев идеальной жидкостью. М.: Наука, 1978. 352 с.

3. Довгий С.О., Буланчук Г.Г., Буланчук О.М. Вихрові течії ідеальної рідини. Класичні моделі та метод дискретних вихорів: монографія. Маріуполь: ПДТУ, 2016. $341 \mathrm{c}$.

4. Белоцерковский С.М., Котовский В.Н., Ништ М.И., Федоров Р.М. Математическое моделирование плоскопараллельного отрывного обтекания. М.: Наука. Физ.-мат. лит., 1988. 232 с.

5. Шлихтинг Г. Теория пограничного слоя. М.: Наука, 1974. 712 с.

6. Loitsyanskii L.G. Laminar Boundary Layer (Fizmatgiz, Moscow, 1962) [in Russian].

Надійшла 20.05.2021. 


\title{
Численная схема расчета пограничного слоя при моделировании методом дискретных вихрей
}

\author{
С.А. Довгий
}

Институт телекоммуникаций и глобального информационного пространства,

Киев, Украина

E-mail: itelua@kv.ukrtel.net

Г.Г. Буланчук

ДВНЗ "Приазовский государственный технический университет", Мариуполь, Украина

E-mail:ggbulan7@gmail.com

О.Н. Буланчук

Донецкий государственный университет управления, Мариуполь, Украина

E-mail: obulan65@gmail.com

В данной работе для определения точки отрыва течений с большими числами Рейнольдса при обтекании гладких тел предлагается шеститочечная конечноразностная численная схема расчета уравнения Прандтля ламинарного пограничного слоя. Входными данными для данной схемы являються результаты моделирования методом дискретных вихрей в рамках модели идеальной жидкости. Профиль скорости в окрестности критической точки определяется с аналитического решения. Полученная система линейных алгебраических уравнений решается методом прогонки. Поскольку коэффициенты системы являются нелинейными, то для нахождения решения используется метод итераций. Толщина пограничного слоя определяется в процессе решения. Точка отрыва и циркуляции сходящих вихрей определяются из расчета пограничного слоя. Затем в точке отрыва моделируется отрыв свободных вихрей, динамика которых находится в рамках метода дискретных вихрей. Схема была апробирована на задачи обтекания цилиндра и показала хорошие результаты по сравнению с экспериментальным данным и расчетами других авторов.

Ключевые слова: метод дискретных вихрей, уравнение Прандтля, уравнение пограничного слоя, точка отрыва, сход вихрей. 